University of Wollongong

Research Online

Australian Institute for Innovative Materials -

Papers

Australian Institute for Innovative Materials

2013

Simply mixed commercial red phosphorus and carbon nanotube composite with exceptionally reversible sodium-ion storage

Wei-Jie Li

University of Wollongong, w1347@uowmail.edu.au

Shulei Chou

University of Wollongong, shulei@uow.edu.au

Jia-Zhao Wang

University of Wollongong

Hua-Kun Liu

University of Wollongong, hua@uow.edu.au

S X. Dou

University of Wollongong, shi@uow.edu.au

Follow this and additional works at: https://ro.uow.edu.au/aiimpapers

Part of the Engineering Commons, and the Physical Sciences and Mathematics Commons

Research Online is the open access institutional repository for the University of Wollongong. For further information contact the UOW Library: research-pubs@uow.edu.au 


\title{
Simply mixed commercial red phosphorus and carbon nanotube composite with exceptionally reversible sodium-ion storage
}

\author{
Abstract \\ Recently, sodium ion batteries (SIBs) have been given intense attention because they are the most \\ promising alternative to lithium ion batteries for application in renewable power stations and smart grid, \\ owing to their low cost, their abundant natural resources, and the similar chemistry of sodium and lithium. \\ Elemental phosphorus $(P)$ is the most promising anode materials for SIBs with the highest theoretical \\ capacity of $2596 \mathrm{~mA} \mathrm{~h} \mathrm{g-1,} \mathrm{but} \mathrm{the} \mathrm{commercially} \mathrm{available} \mathrm{red} \mathrm{phosphorus} \mathrm{cannot} \mathrm{react} \mathrm{with} \mathrm{Na}$ \\ reversibly. Here, we report that simply hand-grinding commercial microsized red phosphorus and carbon \\ nanotubes (CNTs) can deliver a reversible capacity of $1675 \mathrm{~mA} \mathrm{~h} \mathrm{g-1} \mathrm{for} \mathrm{sodium} \mathrm{ion} \mathrm{batteries} \mathrm{(SIBs),} \mathrm{with}$ \\ capacity retention of $76.6 \%$ over 10 cycles. Our results suggest that the simply mixed commercial red \\ phosphorus and CNTs would be a promising anode candidate for SIBs with a high capacity and low cost.

\section{Keywords} \\ ion, sodium, reversible, exceptionally, composite, storage, nanotube, simply, carbon, phosphorus, red, \\ commercial, mixed

\section{Disciplines} \\ Engineering | Physical Sciences and Mathematics

\section{Publication Details} \\ Li, W., Chou, S., Wang, J., Liu, H. \& Dou, S. (2013). Simply mixed commercial red phosphorus and carbon \\ nanotube composite with exceptionally reversible sodium-ion storage. Nano Letters: a journal dedicated \\ to nanoscience and nanotechnology, 13 (11), 5480-5484.
}




\section{Simply Mixed Commercial Red Phosphorus and Carbon Nanotube Composite with Exceptionally Reversible Sodium-ion Storage}

Wei-Jie Li, ${ }^{\dagger}$ Shu-Lei Chou, ${ }^{\dagger} *$ Jia-Zhao Wang, ${ }^{\dagger}$ Hua-Kun Liu, ${ }^{\dagger}$ Shi-Xue Dou ${ }^{\dagger}$

$\dagger$ Institute for Superconducting and Electronic Materials, University of Wollongong, Wollongong, NSW 2522 Australia.

ABSTRACT: Recently, sodium ion batteries (SIBs) have been given intense attention because they are the most promising alternative to lithium ion batteries for application in renewable power stations and smart grid, owing to their low cost, their abundant natural resources, and the similar chemistry of sodium and lithium. Elemental phosphorus $(\mathrm{P})$ is the most promising anode materials for SIBs with the highest theoretical capacity of $2596 \mathrm{mAh} \mathrm{g}^{-1}$, but the commercially available red phosphorus cannot react with $\mathrm{Na}$ reversibly. Here, we report that simply handgrinding commercial micro-sized red phosphorus and carbon nanotubes (CNTs) can deliver a reversible capacity of $1675 \mathrm{mAh} \mathrm{g}^{-1}$ for sodium ion batteries (SIBs), with capacity retention of $76.6 \%$ over 10 cycles. Our results suggest that the simply mixed commercial red phosphorus and CNTs would be a promising anode candidate for SIBs with high capacity and low cost.

KEYWORDS: Commercial red phosphorus, carbon nanotubes network, reversible cycle, sodium ion battery. 
Looking forward to the energy future of humanity, renewable energy will definitely the most sustainable way to solve many social and environmental problems. How to store the variable renewable energy in an efficient and cheap way would be a great challenge. The most promising energy storage systems should combine the features of relatively high energy density, good power capability, enviromental friendliness, and low cost. ${ }^{1}$ Recently, sodium ion batteries (SIBs) have been given intense attention because they are the most promising alternative to lithium ion batteries for application in renewable power stations, owing to their low cost, their abundant natural resources, and the similar chemistry of sodium and lithium. In the last ten years, a large variety of host materials have been demonstrated as sodium ion storage cathodes, as summarized in recent review papers, ${ }^{2}$ such as sodium transition metal oxides ${ }^{3}$ and $\mathrm{MFe}(\mathrm{CN})_{6}(\mathrm{M}=\mathrm{Na}, \mathrm{K}) .{ }^{4}$ In comparison, there have been few investigations on anode materials for SIBs. In the light of the successful experience with carbon anodes in lithium ion batteries (LIBs), carbonaceous materials, such as hard carbons,${ }^{5-9}$ carbon nanospheres ${ }^{10}$ and nanowires, ${ }^{11}$ and graphene, ${ }^{12}$ have been introduced as anode materials for SIBs. Subsequently, Sn and Sb-based materials ${ }^{13-16}$ have been studied as anode for sodium ion batteries, as they have high reversible capacity, but their specific capacities are still relatively low $\left(500-800 \mathrm{mAh} \mathrm{g}^{-1}\right)$.

Elemental phosphorus $(\mathrm{P})$ is an attractive anode material, which can give a high theoretical specific capacity of $2596 \mathrm{mAh} \mathrm{g}^{-1}$ to form $\mathrm{Na}_{3} \mathrm{P}$ phase. Phosphorus has three allotropes, white, black, and red. Among these allotropes, white phosphorus is not chemically stable, and synthesis of black phosphorus is not facile, as it needs an inert atmosphere under high pressure. ${ }^{17-18}$ In comparison, red phosphorus is commercially available with ease. For sodium ion storage, recently, Qian et al. ${ }^{19}$ and Kim et al. ${ }^{20}$ reported that an amorphous phosphorus composite with carbon prepared by high-energy mechanical milling could deliver a high capacity of $1764 \mathrm{mAh}$ $\mathrm{g}^{-1}$ at the current density of $250 \mathrm{~mA} \mathrm{~g}^{-1}$ and $1890 \mathrm{mAh} \mathrm{g}^{-1}$ at current density of $143 \mathrm{~mA} \mathrm{~g}^{-1}$, 
respectively. Based on their reports, ${ }^{19,20}$ the commercially available red phosphorus with microsize particle shows large initial specific capacity but cannot react with Na reversibly. During the long and vigorous high-energy ball milling, bulk commercial phosphorus particles were crushed into amorphous nanoparticles, highly dispersing in a conductive carbon matrix to achieve a reversible sodium ion storage. However, crystalline $\mathrm{P}$ can reversibly react with Li ions via the electronic improvement of $\mathrm{P}$ by vaporization and condensation on mesoporous carbon. ${ }^{21}$ The electronic modification was the main reason for the reversible de/insertion of Li ions into/out of crystalline red phosphorus. Therefore, the question was raised here as to whether commercial red phosphorus with large particles can react reversibly with $\mathrm{Na}$ just via improving the electronic conductivity.

Making carbon composite materials is one effective solution to improve conductivity in the battery field. Carbon nanotubes (CNTs) could be a promising candidate to serve as both the conductive network and the buffer to alleviate the stress from volume expansion, owing to its advantages of a unique network structure with low electrical resistivity and good mechanical properties, such as strength, stiffness, and resilience..$^{22-24}$ All the previous reports used different dedicated chemical or physical methode to prepare composite materials, which would also increase the cost of the materials. Herein, we used the commercial red phosphorus in micrometer size simply mixed with CNTs by hand grinding to unexpectedly achieve highly reversible sodium storage in commercially available red phosphorus. The simplicity of the preparation method and the highly reversible sodium storage are likely to make a great impact in the reseach on sodium battery materials.

Figure 1 shows the Raman spectra and X-ray diffraction (XRD) patterns for commercial red phosphorus (P), carbon nanotubes (CNTs), and P/CNT composite. The XRD pattern of the 
commercial red $\mathrm{P}$ shows a sharp diffraction peak at $15^{\circ}$ (Figure 1(a)), suggesting a mediumrange ordered structure..$^{25}$ The multiwall CNTs show two peaks at $26^{\circ}$ and $44^{\circ}$, respectively. After grinding red phosphorus with CNTs for $1 \mathrm{~h}$, there is no new phase in the XRD pattern of the composite. The composite consists of commercial red phosphorus and carbon nanotubes (Figure 1(a)). The Raman spectra further demonstrate that the composite only exhibits peaks of red phosphorus and carbon nanotubes (Figure 1(b)). Three bands from $300 \mathrm{~cm}^{-1}$ to $500 \mathrm{~cm}^{-1}$ can be assigned to red phosphorus. The two peaks at $1324 \mathrm{~cm}^{-1}$ and $1571 \mathrm{~cm}^{-1}$ are the D-band and Gband of carbon nanotubes, respectively. Moreover, no shift in the D-band of the carbon nanotubes can be observed, indicating that there are no interactions between the $\mathrm{P}$ and the CNTs. X-ray photoelectron spectroscopy (XPS) was used to further confirm the surface interaction between CNTs and red phosphorus. The results show that the composite show the same position of $\mathrm{C}_{1 \mathrm{~s}}$ and $\mathrm{P}_{2 \mathrm{p}}$ with pristine CNTs and red phosphorus, respectively, indicating that there is no surface interaction between CNTs and red phosphorus (see Figure S1 in Supporting Information). Hence, after grinding for 1 hour, the starting red phosphorus retains its pristine structure, confirming that it is only physically mixed with the carbon nanotubes to form the P/CNT composite. Figure 2 shows the morphology of the P/CNT composite. The particle size of bulk commercial red phosphorus (Figure S2(a) in the Supporting Information) was broken down to an average of $3 \mu \mathrm{m}$ after grinding (Figure 2(a)). Moreover, the red phosphorus particles were wrapped up by the CNTs, which would be helpful for increasing the electronic conductivity of the red phosphorus (Figure 2(b). The high resolution transmission electron microscopy (HRTEM) image was shown in Figure 2(c). The typical morphology of CNTs with multi-layers of graphene can be observed on the surface of phosphorus. 

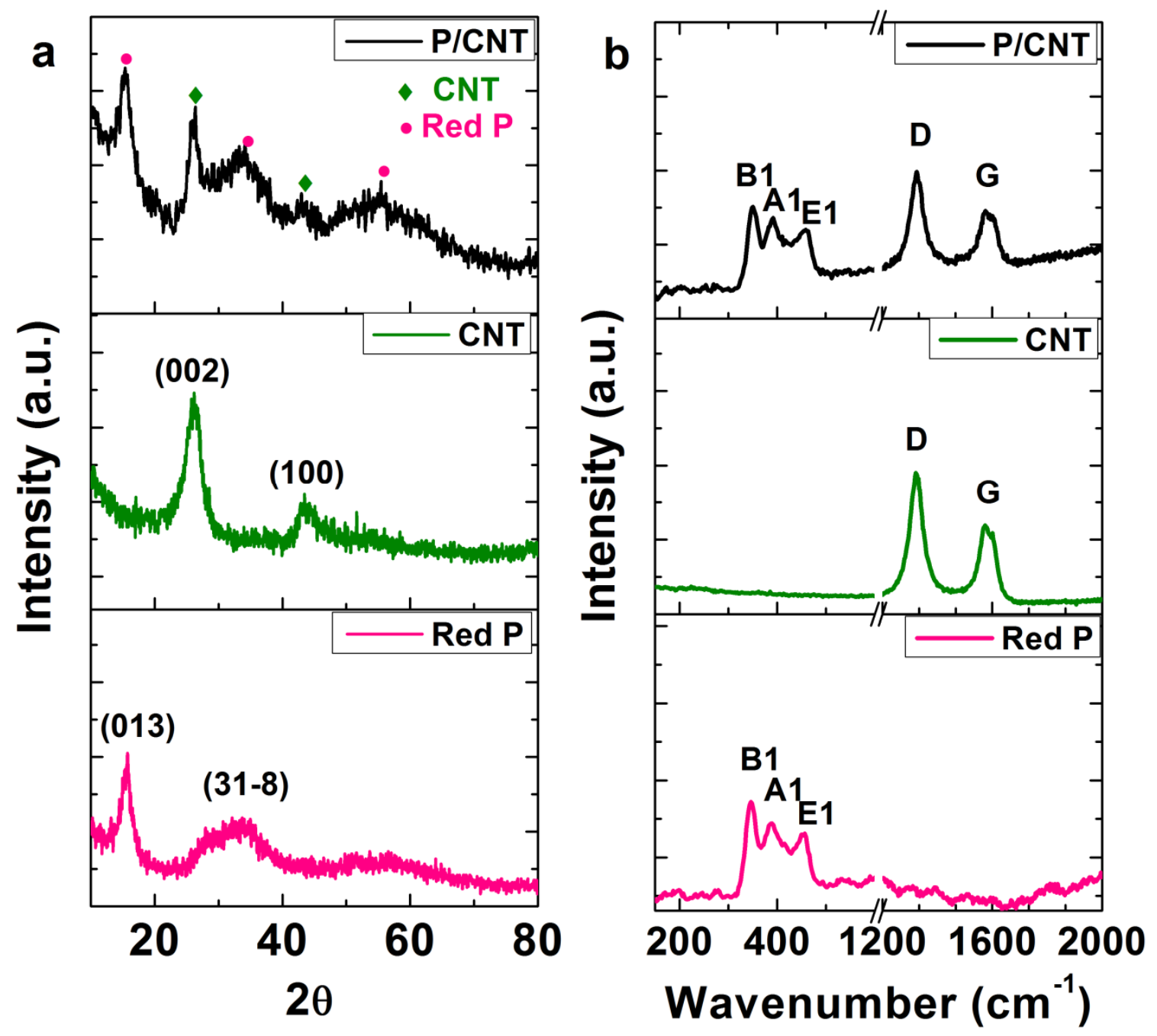

Figure 1. (a) XRD and (b) Raman spectra of the commercial red P, CNTs, and P/CNT composite. 
a

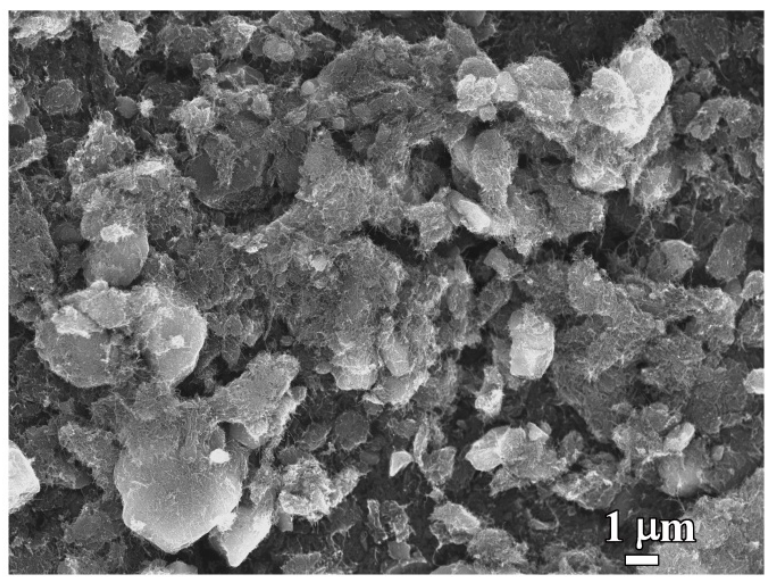

c

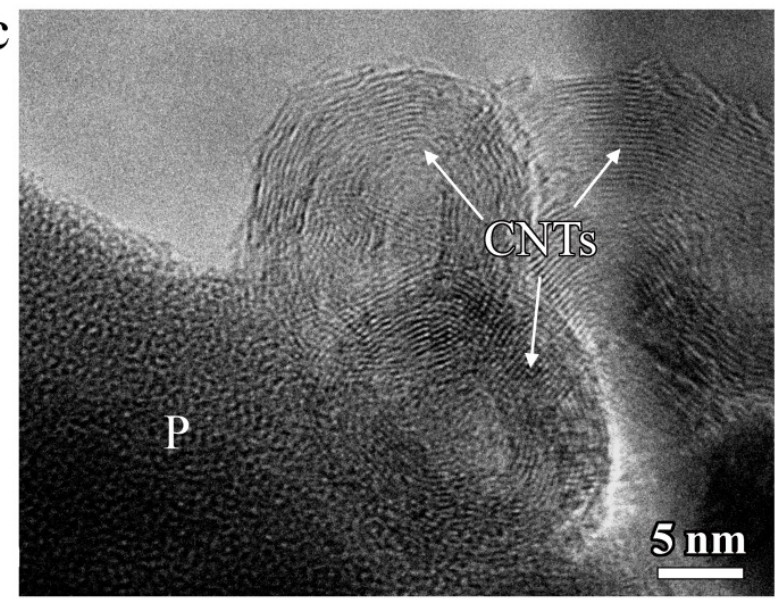

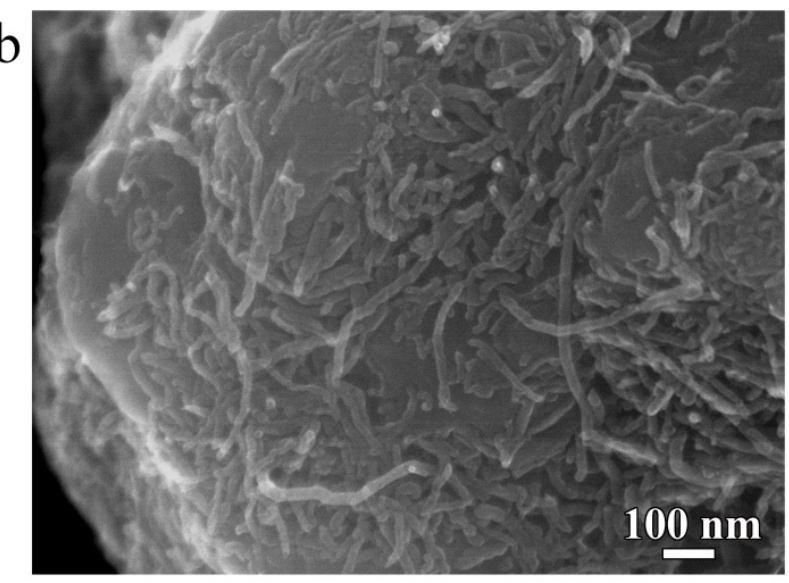

$100 \mathrm{~nm}$

Figure 2. (a, b) SEM and (c) HRTEM images of P/CNT composite.

Figure 3(a) presents the charge/discharge curves of the commercial $\mathrm{P}$ and P/CNT composite between 0 and $1.5 \mathrm{~V}$ at a current density of $143 \mathrm{~mA} \mathrm{~g}^{-1}$. The commercial red phosphorus delivered an initial discharge capacity of $\sim 1600 \mathrm{mAh} \mathrm{g}^{-1}$. Its initial charge capacity was only 50 $\mathrm{mAh} \mathrm{g}^{-1}$, however, demonstrating its irreversible electrochemical performance. This result is similar to those reported in literature. ${ }^{19,20}$ The CNT also shows limited reversible capacity for sodium storage with $\sim 300 \mathrm{mAh} \mathrm{g}^{-1}$ initial discharge capacity and $\sim 40 \mathrm{mAh} \mathrm{g}^{-1}$ charge capacity in the first cycle (Figure S3(a) in the Supporting Information). Interestingly, when the commercial red phosphorus was mixed with the CNTs, it exhibited highly reversible charge/discharge capacity. The charge/discharge profiles of the P/CNT composite are similar to those of a reported 
amorphous red P/carbon black composite. ${ }^{19}$ The initial discharge capacity of the P/CNT composite electrode was $\sim 2210 \mathrm{mAh} \mathrm{g}^{-1}$, which is about $40 \%$ larger than that of the red $\mathrm{P}$ one, while the charge capacity was $1530 \mathrm{mAh} \mathrm{g}^{-1}$ in the first charge (Figure 3(a)). The specific capacity was calculated based on the weight of the phosphorus, because the contribution of the carbon nanotubes to the reversible capacity is negligible (only $40 \mathrm{mAh} \mathrm{g}^{-1}$ ).

In order to clarify the reactions of the $\mathrm{P} / \mathrm{CNT}$ composite in SIBs, the $\mathrm{dQ} / \mathrm{dV}$ curves of red $\mathrm{P}$ and P/CNT composite are displayed in Figure 3(b) and (c). One small ( 0.9 V) and two large (below $0.5 \mathrm{~V}$ ) cathodic peaks can be seen in both samples. The peak position for red $\mathrm{P}$ is lower than for the $\mathrm{P} / \mathrm{CNT}$ composite, which is due to the high resistance of the red $\mathrm{P}$ sample. The first small peak (Figure 3(c)) can be attributed to the decomposition of electrolyte in the formation of a solid-electrolyte interphase (SEI) layer on the surface of the active materials. The second cathodic peak located in the range of $0.2-0.35 \mathrm{~V}$ corresponds to the sodium ion insertion reaction to form the $\mathrm{Na}_{x} \mathrm{P}$ compounds. The peak at around $0.1 \mathrm{~V}$ is ascribed to the formation of fully charged $\mathrm{Na}_{3} \mathrm{P}$ phase. ${ }^{20}$ In the reversed process, a very weak peak can be observed for the commercial red phosphorus (Figure 3(c)), demonstrating the irreversible desodiation process, while the P/CNT composite has one sharp peak and two small shoulder peaks, indicating a reversible sodiation/desodiation process. This phenomenon is possibly owing to the improvement of electronic conductivity after CNT addition. 

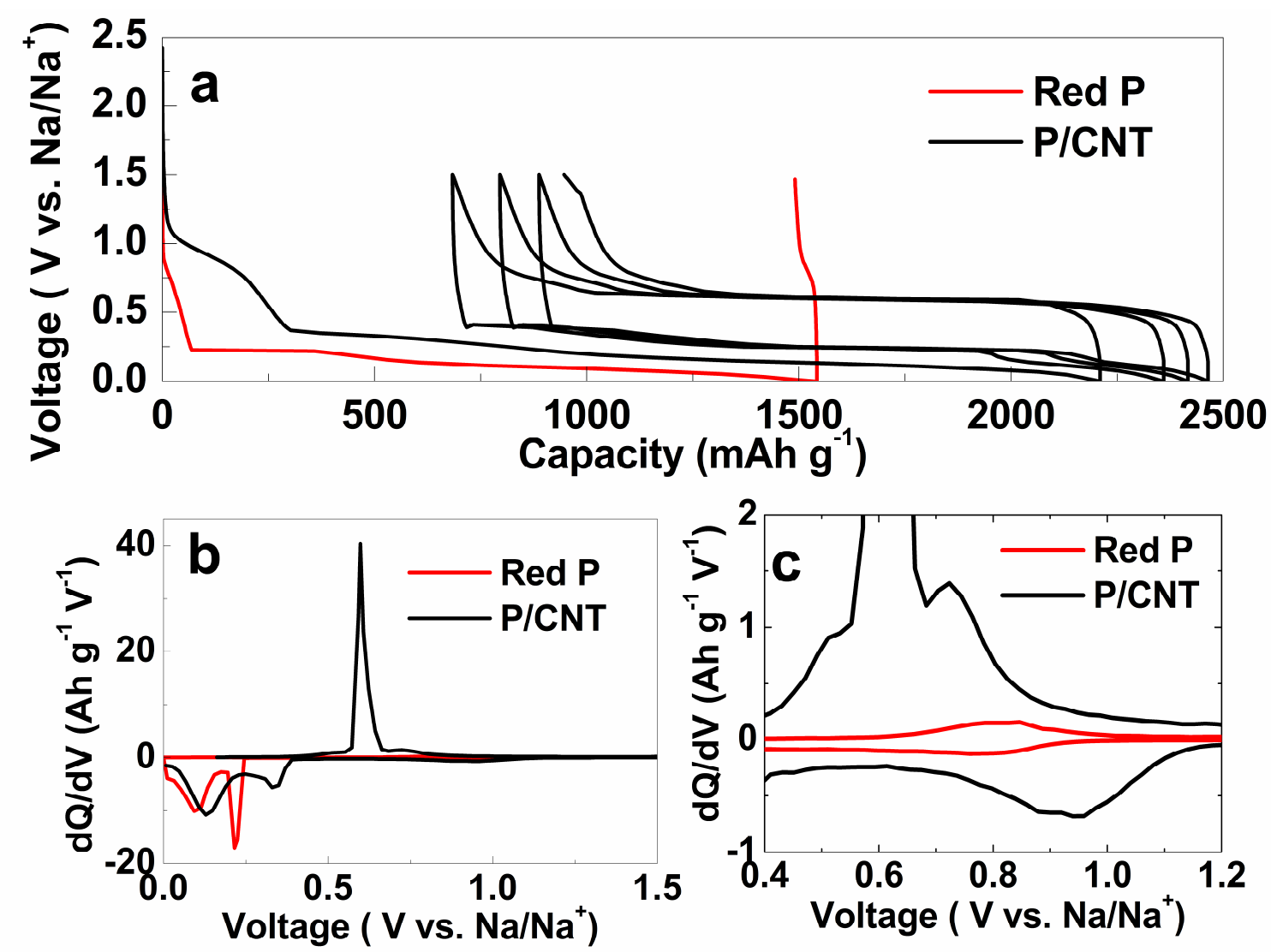

Figure 3. Charge-discharge curves (a) and $\mathrm{dQ} / \mathrm{dV}$ ((b) and (c)) curves of red $\mathrm{P}$ and $\mathrm{P} / \mathrm{CNT}$ composite at current density of $143 \mathrm{~mA} \mathrm{~g}^{-1}$ from $0-1.5 \mathrm{~V}$; (c) is the enlargement of (b) from 0.4 to $1.2 \mathrm{~V}$.

Electrochemical impedance spectroscopy (EIS) was conducted to further investigate the conductivity enhancement. Figure S4 in the Supporting Information shows the Nyquist plots of the P/CNT composite electrode compared with commercial P electrodes in the charged state at $0.65 \mathrm{~V}$ (vs. $\mathrm{Na}^{+} / \mathrm{Na}$ ). The impedance curves of both P/CNT and red $\mathrm{P}$ show two semicircles in the medium frequency and the low frequency regions, which could be assigned to the sodium ion diffusion through the solid electrolyte interphase (SEI) film $\left(\mathrm{R}_{\mathrm{x}}\right)$ and the charge transfer resistance $\left(\mathrm{R}_{\mathrm{cc}}\right)$, respectively. The $\mathrm{R}_{\mathrm{ct}}$ is calculated using the equivalent circuit shown in the inset of Figure S4. The $\mathrm{R}_{\mathrm{ct}}$ value of the commercial red $\mathrm{P}$ was $7500 \bullet$, but after the addition of CNTs, 
the $\mathrm{R}_{\mathrm{ct}}$ value significantly decreased to $3900 \bullet$. This demonstrates that addition of CNTs can significantly improve the conductivity of bulk commercial red $\mathrm{P}$, delivering reversible charge/discharge capacity.

To further confirm the function of CNTs in the composite, P/carbon black (CB) composite was prepared by hand grinding for $1 \mathrm{~h}$, in which the weight percent of carbon black (CB) was also $30 \%$. The cycling performance of P/CNT compared with $\mathrm{P} / \mathrm{CB}$ is shown in Figure 4(a). When commercial red phosphorus was mixed with $30 \mathrm{wt} \% \%$ carbon black, its initial discharge capacity (2200 $\mathrm{mAh} \mathrm{g}^{-1}$ ) was increased compared with the pristine red phosphorus (1530 $\mathrm{mAh} \mathrm{g}^{-1}$ ). Although the P/carbon black electrode could charge-discharge reversibly, the discharge capacity dropped dramatically, down to $770 \mathrm{mAh} \mathrm{g}^{-1}$ for the $2^{\text {nd }}$ cycle and only $90 \mathrm{mAh} \mathrm{g}^{-1}$ for the $3^{\text {rd }}$ cycle. In comparison with the $\mathrm{P} /$ carbon black composite, the reversible cycling performance of the P/CNT composite was much better. After 10 cycles, the discharge capacity was $1283.3 \mathrm{mAh} \mathrm{g}^{-1}$, with $76.6 \%$ reversible capacity retention. A specific capacity of $750 \mathrm{mAh} \mathrm{g}^{-1}$ can be obtained after 20 cycles. The cycling stabilities of the composites with different weight percentage of CNTs were shown in Figure 4(b) and Figure 4 (c). If the specific capacity is calculated based on the weight of P only (Figure 4(b)), the initial discharge capacity increased as the weight ratio of CNTs increased from $10 \%$ to $50 \%$. Moreover, the cycle stability was also improved. However, when capacity was calculated based on the weight of the total composite, the composite with 30 wt.\% CNTs show the highest specific capacity and the best stable cycling performance. (Figure 4(c)). Cycling stability could be further improved by designing an appropriate binder which has both good cohesiveness and favorable mechanical properties. 

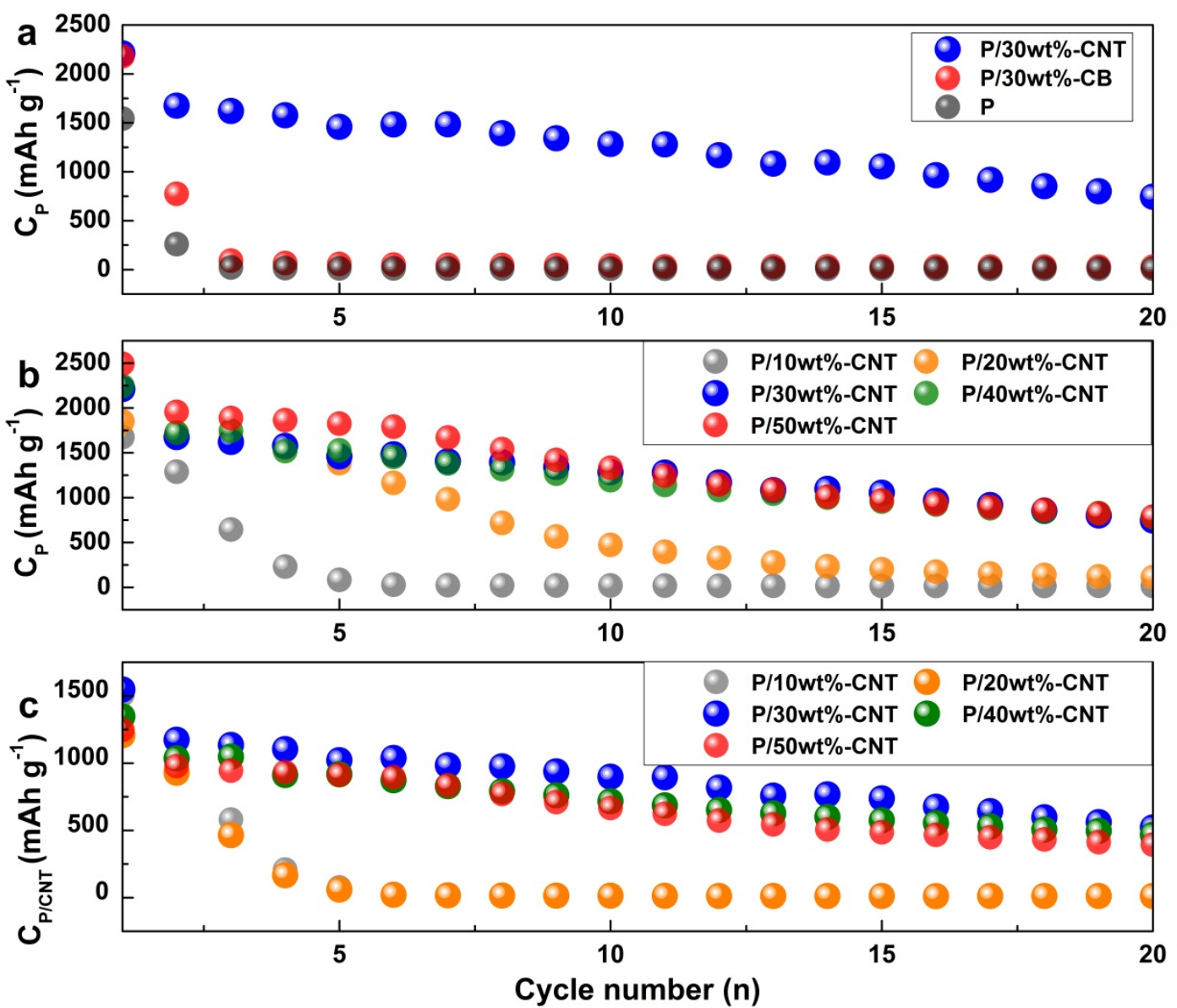

Figure 4. Cycling performance of (a) P/30wt\%-CNT composites compared with P/carbon black composite, and $(b, c) P / C N T$ composites with different $\mathrm{CNT}$ contents. $\mathrm{C}_{\mathrm{P}}$ and $\mathrm{C}_{\mathrm{P} / \mathrm{CNT}}$ is for specific capacity calculated based on the weight of $\mathrm{P}$ and P/CNT composites, respectively.

The commercial red phosphorus wrapped with CNTs can reversibly cycle better than when mixed with carbon black. The most likely reason would be that the CNTs could form a network structure and increase the buffer space between the $\mathrm{P}$ particles as shown in Figure 5. Since the volume expansion is around $491 \%$ during the phase transition from phosphorus to $\mathrm{Na}_{3} \mathrm{P}$ after the initial discharge, CNTs, which have excellent mechanical properties, can effectively buffer enormous stresses and thus reduce the rate of bulk red phosphorus pulverization. In LIBs, the 
CNTs' network structure as a soft matrix has been used to alleviate the stress from volume expansion of $\mathrm{Si}^{23 \mathrm{a}} \mathrm{Sn}^{24} \mathrm{SnO}_{2}{ }^{26}$ and $\mathrm{SnSb}^{27}$. For sodium ion batteries, recently, Wang and coworkers used CNTs as a matrix and a conducting network to provide good contact between isolated $\mathrm{SnO}_{2}$ particles and to buffer the volume expansion of $\mathrm{SnO}_{2}$ nanocrystals. ${ }^{28}$ The network structure provides pathways for electron transport that promote good connections between the red phosphorous particles and reduce the influence of volume expansion on the connections not only between the red phosphorus particles, but also between red phosphorus and the current collector. This point was supported by the morphology of the P/carbon black (Figure S5) and P/CNT (Figure S6) composite electrodes before and after one cycle. It is apparent that the small carbon black particles didn't completely cover the big phosphorus particles, as shown in Figure S5(a). In contrast, the bulk red phosphorus particles were wrapped well by the CNT network in the P/CNT composite (Figure S6(a)). That is why the P/CNT composite electrode has better electronic conductivity than the P/carbon black composite electrode. After one cycle, there is a big change on the surface of the P/carbon black composite electrode. The fluffy morphology can be observed in Figure S5(b). It is due to both the formation of the SEI layer and huge volume change when sodium ions are inserted into and extracted from $\mathrm{P}$, which induces strong stresses on the phosphorus particles and causes pulverization and rapid capacity fading (Figure 4). A similar phenomenon also can be observed when Li ions are inserted into and de-inserted from $\mathrm{Si}$ particles. ${ }^{29}$ In contrast, the surface of the P/CNT composite electrode did not change much after 1 cycle, as shown in Figure S6(b). The red phosphorus particles cracked into small particles, but were still wrapped by the CNTs (Figure S6(c), which maintained the electronic connections among the red phosphorus particles. As a result, the P/CNT composite electrode could still be cycled beyond the first few cycles, with a relatively stable capacity (Figure 4). 


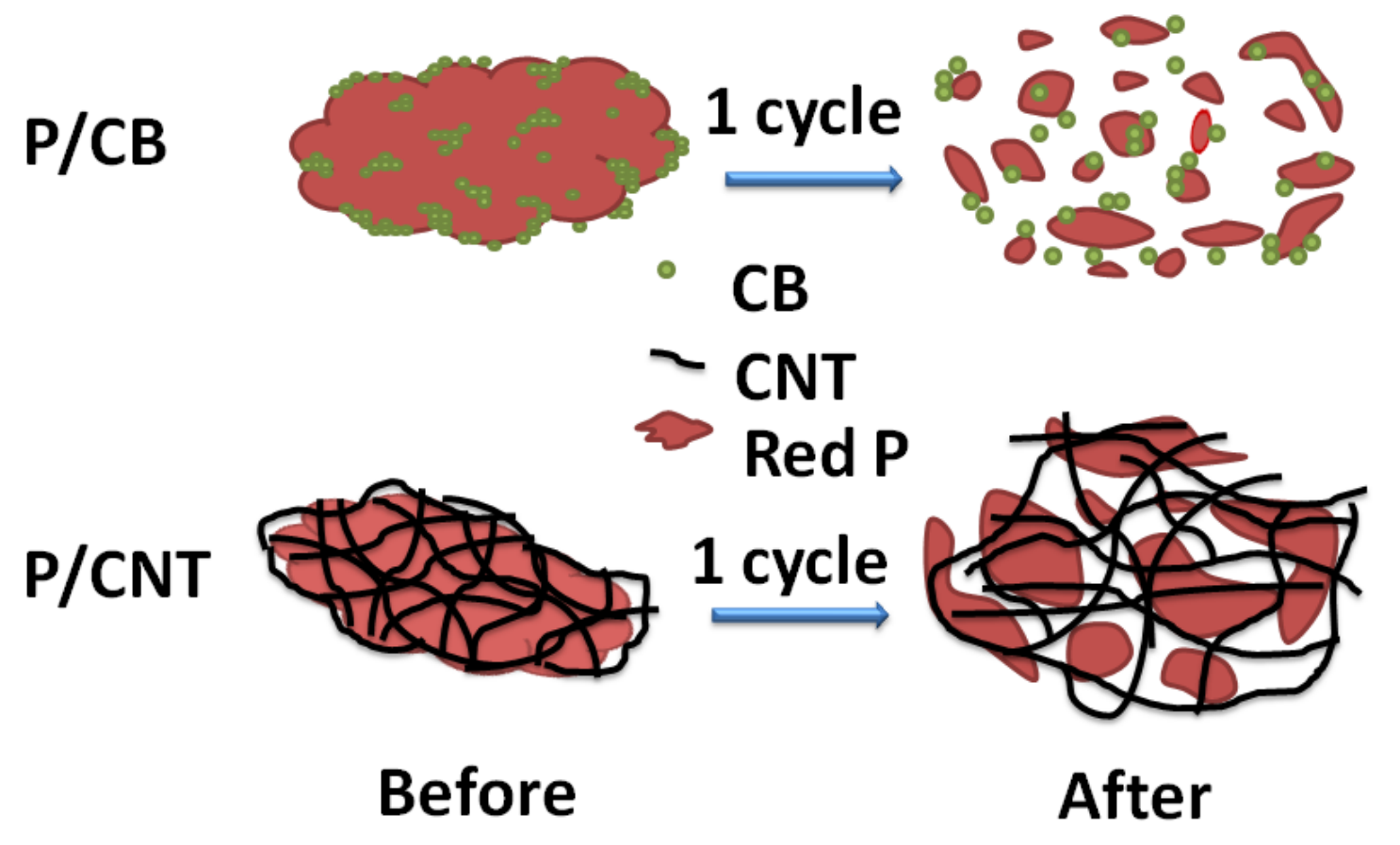

Figure 5. Proposed function of CNTs during the volume expansion.

In summary, we prepared a P/CNT composite simply by hand grinding commercial red P with carbon nanotubes. The P/CNT composite can be cycled reversibly, with an initial discharge capacity of $2210 \mathrm{mAh} \mathrm{g}^{-1}$, and $76.6 \%$ of the initial reversible capacity still delivered after 10 cycles. CNTs play a crucial role in the reversibility of the commercial P/CNT composite. The network structure of the CNTs serves to effectively buffer the enormous stresses from the volume expansion of the $\mathrm{P}$ particles and reduce the rate of pulverization of particles. On the other hand, the CNT network provides pathways for electron transport, which is helpful for maintaining the connections not only between the red phosphorus particles, but also between the red phosphorus and the current collector. Our results suggest that the simply mixed commercial red phosphorus and CNTs would be a promising candidate for the next generation anode material for sodium ion batteries with high capacity and low cost. 


\section{ASSOCIATED CONTENT}

Supporting Information. Experimental details for the material preparation, and the structural and electrochemical characterization, along with the additional supporting data.

\section{AUTHOR INFORMATION}

\section{Corresponding Author}

* E-mail: shulei@uow.edu.au

\section{Notes}

The authors declare no competing financial interest.

\section{ACKNOWLEDGMENT}

The work is supported by the Australian Research Council through a Discover project (DP110103909) and a Linkage Project (LP120200432). The authors would like to also thank Dr Tania Silver for critical reading of the manuscript and Dr Jun Wang for the Raman testing.

\section{REFERENCES}

(1) a) Dunn, B.; Kamath, H.; Tarascon, J. M. Science, 2011, 334(6058), 928-935; b) Yang, Z. G.; Zhang, J. L.; Kintner-Meyer, M. C. W.; Lu, X. C.; Choi, D. W.; Lemmon, J. P.; Liu, J. Chem. Rev. 2011, 111(5), 3577-3613.

(2) a) Ong, SP; Chevrier, VL; Hautier, G; Jain, A; Moore, C; Kim, S.; Ma, XH; Ceder, G. Energy Environ. Sci. 2011, 4(9), 3680-3688. b) Palomares, P.; Serras, P.; Villaluenga I.; Hueso, K. B.; Carretero-Gonzalez, J.; Rojo, T. Energy Environ. Sci., 2012, 5, 5884-5901. 
(3) a) Berthelot, R.; Carlier, D.; Delmas, C. Nature Mater. 2011, 10, 74-80; b) Yabuuchi, N.; Kajiyama, M. Iwatate, J.; Nishikawa, H.; Hitomi, S.; Okuyama, R.; Usui, R.; Yamada, Y.; Komaba S. Nature Mater. 2012, 11, 512-517.

(4) a) Qian, J. F.; Zhou, M.; Cao, Y. L.; Ai, X. P.; Yang, H. X. Adv. Energy Mater. 2012, 2(4), 410-414. b) Lu, Y. H.; Wang, L.; Cheng, J. Q.; Goodenough, J. B. Chem. Commun. 2012, 48(52), 6544-6546; c) Wang, L.; Lu, Y.; Liu, J.; Xu, M.; Cheng, J.; Zhang, D.; Goodenough, J. B. Angew. Chem., Int. Ed. 2013, 52, $1964-1967$.

(5) Alcántara, R.; Jiménez Mateos J. M.; Tirado, J. L. J. Electrochem. Soc. 2002, 149(2), A201A205.

(6) Stevens, D. A.; Dahn, J. R. J. Electrochem. Soc. 2000, 147(4), 1271-1273.

(7) Alcantara, R.; Lavela, P. G.; Ortiz, F.; Tirado, J. L. Electrochem. Solid-State Lett. 2005, 8(4), A222-A225.

(8) Komaba, S.; Murata, W.; Ishikawa, T.; Yabuuchi, N.; Ozeki, T.; Nakayama, T.; Ogata, A.; Gotoh, K.; Fujiwara, K. Adv. Funct. Mater. 2011, 21(20), 3859-3867.

(9) Xing, W. B.; Dahn, J. R. J. Electrochem. Soc. 1997, 144(4), 1195-1201.

(10) Tang, K.; Fu, L. J.; White, R. J.; Yu, L. H.; Titirici, M.-M.; Antonietti, M.; Maier, J. Adv. Energy Mater. 2012, 2(7), 873-877.

(11) Cao, Y. L.; Xiao, L. F.; Sushko, M. L.; Wang, W.; Schwenzer, B.; Xiao, J.; Nie, Z. M.; Saraf, L. V.; Yang, Z. G.; Liu, J. Nano Lett. 2012, 12(7), 3783-3787.

(12) Wang, Y. X.; Chou, S. L.; Liu H. K.; Dou, S. X. Carbon 2013, 57, 202-208. 
(13) Xu, Y.; Zhu, Y.; Liu, Y.; Wang, C. Adv. Energy Mater. 2013, 3(1), 128-133.

(14) Xiao, L. F.; Cao, Y. L.; Xiao, J.; Wang, W.; Kovarik, L.; Nie, Z. M.; Liu, J. Chem. Commun. 2012, 48(27), 3321-3323.

(15) Qian, J. F.; Chen, Y.; Wu, L.; Cao, Y. L.; Ai, X. P.; Yang, H. X. Chem. Commun. 2012, 48(56), 7070-7072.

(16) Darwiche, A.; Marino, C.; Sougrati, M. T.; Fraisse, B.; Stievano, L.; Monconduit, L. J. Am. Chem. Soc. 2012, 134(51), 20805-20811.

(17) Park, C. M.; Sohn, H. J. Adv. Mater. 2007, 19(18), 2465-2468.

(18) Wang, L.; He, X. M.; Li, J. J.; Sun, W. T.; Gao, J.; Guo, J. W.; Jiang, C. Y. Angew. Chem., Int. Ed. 2012, 51(36), 9034-9037.

(19) Qian, J. F.; Wu, X. Y.; Cao, Y. L.; Ai, X. P.; Yang, H. X. Angew. Chem., Int. Ed. 2013, 52(17), 4633-4636.

(20) Kim, Y.; Park, Y.; Choi, A.; Choi, N. S.; Kim, J.; Lee, J.; Ryu, J. H.; Oh, S. M.; Lee, K. T. Adv. Mater. 2013, 25(22), 3045-3049.

(21) Marino, C.; Boulet, L.; Gaveau, P.; Fraisse, B.; Monconduit, L. J. Mater. Chem. 2012, 22(42), 22713-22720.

(22) Lee, S. W.; Yabuuchi, N.; Gallant, B. M.; Chen, S.; Kim, B. S.; Hammond, P. T.; ShaoHorn, Y. Nat. Nanotechn. 2010, 5(7), 531-537. 
(23) a) Wang, W.; Kumta, P. N. ACS Nano 2010, 4(4), 2233-2241; b) Tang W.; Gao X. W.; Zhu Y. S.; Yue Y. H.; Shi Y.; Wu Y. P.; Zhu K. J. Mater. Chem. 2012, 22, 20143-20145; c) Tang W.; Hou Y. Y.; Wang X. J.; Bai Y.; Zhu Y. S.; Sun H.; Yue Y. B.; Wu Y. P.; Zhu K.; Holze R. J. Power Sources, 2012, 197, 330-333.

(24) Wang, Y.; Wu, M. H.; Jiao, Z.; Lee, J. Y. Chem. Mater. 2009, 21(14), 3210-3215.

(25) Zaug, J. M.; Soper, A. K.; Clark, S. M. Nat. Mater. 2008, 7(11), 890-899.

(26) Chen G.; Wang Z. Y.; Xia D. G. Chem. Mater. 2008, 20(22), 6951-6956.

(27) a) Park M. S.; Needham S. A.; Wang G. X.; Kang Y. M.; Park J. S.; Dou S. X.; Liu H. K. Chem. Mater. 2007, 19, 2406-2410; b) Chen W. X.; Lee J. Y.; Liu Z. L. Carbon, 2003, 41(5), 959-966.

(28) Wang Y.; Su D. W.; Wang C. Y.; Wang G. X. Electrochem. Commun. 2013, 29, 8-11.

(29) Wu, H.; Yu, G.; Pan, L.; Liu, N.; McDowell, M. T. Bao, Z.; Cui, Y. Nat. Commun. 2013, 4, 1943. 